\title{
Accumulation of polybrominated diphenyl ethers in the brain compared with the levels in other tissues among different vertebrates from an e-waste recycling site ${ }^{\text {ir }}$
}

\author{
Yaxian Zhao ${ }^{\mathrm{a}, \mathrm{b}}$, Yuanyuan $\mathrm{Li}^{\mathrm{b}, \mathrm{c}}$, Xiaofei Qin ${ }^{\mathrm{c}}$, Qinqin Lou ${ }^{\mathrm{b}}$, Zhanfen Qin ${ }^{\mathrm{b}, \mathrm{c}^{*} \text { * }}$ \\ ${ }^{a}$ Institute for Environmental Reference Materials of Ministry of Environmental Protection, Beijing 100029, China \\ ${ }^{\mathrm{b}}$ State Key Laboratory of Environmental Chemistry and Ecotoxicology, Research Center for Eco-environmental Sciences, Chinese Academy of Sciences, \\ Beijing 100085, China \\ ${ }^{\mathrm{c}}$ University of Chinese Academy of Science, Beijing 100049, China
}

\section{A R T I C L E I N F O}

\section{Article history:}

Received 30 April 2016

Received in revised form

31 August 2016

Accepted 31 August 2016

Available online 6 September 2016

\section{Keywords:}

Polybrominated diphenyl ethers

Accumulation

Brain

Blood-brain barrier

Evolution

\begin{abstract}
A B S T R A C T
This study aimed to investigate the accumulation of polybrominated diphenyl ethers (PBDEs) in the brain compared with that in other tissues among different vertebrates. We collected mice, chickens, ducks, frogs, and fish from an e-waste recycling region in Taizhou, China, and measured PBDE concentrations in brain, liver and muscle tissues. The levels of PBDE in the tissues of mice, chickens, ducks, frogs and fish ranged $0.45-206,0.06-18.8,1.83-112,2.75-108$, and $0.02-32.0 \mathrm{ng} / \mathrm{g}$ wet weight, respectively. Preferential distribution in the liver and muscle relative to the brain was observed for PBDEs in mice, chickens, ducks and frogs. However, a high retention in the brain compared to the liver and muscle was observed in fish. Comparison of the brain/liver concentration (B/L) ratios revealed differences in PBDEs accumulation in the brain among these vertebrates. PBDEs accumulation in the brain was greatest in fish, followed by frogs, while the lowest accumulation occurred in the brains of mammals and birds. The findings apparently coincided with the evolution of the blood-brain barrier (BBB) across vertebrates, i.e. the BBB of fish might be less efficient than those of mammals, birds and amphibian. Low brominated congeners (such as BDE-28, BDE-47 and BDE-99) were predominant in the brains of investigated vertebrates, whereas BDE-209 was most abundant in liver and muscle tissues of mice, chickens and ducks. Significant differences in $\mathrm{B} / \mathrm{L}$ ratios among PBDE congeners were found in both mice and chickens $(p<0.05)$. Particularly in mice, the $\mathrm{B} / \mathrm{L}$ ratios of PBDE congeners presented a declining trend with increased bromine number. Our findings suggested that low brominated congeners might have a higher capacity to penetrate the BBB and accumulate in the brain, whereas high brominated congeners such as BDE-209 might have less potency to pass through the barrier. Further experimental studies are needed to confirm our findings.
\end{abstract}

() 2016 Elsevier Ltd. All rights reserved.

\section{Introduction}

The extensive use of polybrominated diphenyl ethers (PBDEs) as flame retardants has resulted in their ubiquitous presence in the environment. Among the three main types of commercially produced PBDEs (penta-, octa-, and deca-BDEs), penta- and octa-BDEs

\footnotetext{
\$ This paper has been recommended for acceptance by Eddy Y. Zeng.

* Corresponding author. State Key Laboratory of Environmental Chemistry and Ecotoxicology, Research Center for Eco-environmental Sciences, Chinese Academy of Sciences, Beijing 100085, China.

E-mail address: qinzhanfen@rcees.ac.cn (Z. Qin).
}

have been nominated for a global ban under the Stockholm Convention (Stockholm Convention, 2009), with their use to be phased out, due to their persistence, bioaccumulation and toxicities. The production of deca-BDEs has ceased in some European countries and in the USA, but they are still used in some developing countries, including China and South Africa (Abafe and Martincigh, 2015; Wan et al., 2013). Despite a declining trend in the levels of PBDEs observed in certain regions, this group of persistent pollutants is still detectable in various environmental media and biotic samples (Barón et al., 2015; Hassan et al., 2013; Yu et al., 2016; Zheng et al., 2015). It has been demonstrated that PBDEs adversely affect the developing brain, resulting in neurodevelopmental disorders (Costa et al., 2014, 2016; Kodavanti et al., 
2015). However, there is little understanding of the accumulation of PBDEs in the brain and their transfer across the blood-brain barrier (BBB).

Generally, the BBB is believed to protect the central nervous system from the entry of toxins (Bernacki et al., 2008). However, there is evidence that the $\mathrm{BBB}$ dose not completely restrict the entry of lipophilic pollutants, which may enter the brain via lipidmediated free diffusion or carrier/receptor-mediated transport (Barón et al., 2015; Pardridge, 2012). PBDEs have been detected in brain tissues from several wildlife species, including fish (Barni et al., 2014; Nilsen et al., 2014), frogs (Li et al., 2014; Liu et al., 2011), river otters (Basu et al., 2007), birds (Voorspoels et al., 2006), polar bears (Gebbink et al., 2008), and dolphins (Barón et al., 2015). Generally, PBDE concentrations in the brain were lower than in other tissues, consistent with protection by the BBB against PBDE accumulation in the brain. However, one study has reported relatively higher concentrations in the brains of fish relative to other tissues (Barni et al., 2014). Bachour et al. (1998) previously speculated that the $\mathrm{BBB}$ of fish was less efficient than that of mammals in terms of its protection against PCB accumulation in the brain. Given these reports of high interspecific variability of PBDEs distributions in the brain, we hypothesized that PBDE accumulation in the brain might vary among a range of vertebrates exposed to similar levels of pollution in the same region.

The study aimed to measure PBDE concentrations in the brains of several vertebrates and to discuss the accumulation of PBDEs in relation to their transfer across the BBB. We collected animal samples in a typical electronic (e) -waste recycling site in Taizhou, Zhengjiang Province, China. Taizhou is known to be a PBDEspolluted area because it has been a site of primary treatment of e-waste for several decades. Previous studies reported high levels of PBDEs in soil, sediment and air samples from this area, with BDE209 as the dominant congener (Han et al., 2009; Tang et al., 2014; Yu et al., 2016). High levels of PBDEs have also been found in wildlife and domestic animals in this area (Liu et al., 2011, 2015; Qin et al., 2011; Yang et al., 2011), suggesting that Taizhou would be an appropriate locale for investigating the bioaccumulation of PBDEs. In particular, collecting biotic samples from different animals from the same site facilitates the comparison of species-specific differences in bioaccumulations of PBDEs. We collected mammals (mice), birds (chickens and ducks), amphibians (frogs), and fish, and measured PBDE concentrations and congener profiles in brain, liver and muscle tissues of these vertebrates to compare accumulations of PBDEs in the brain among different vertebrates. This is the first study investigating differences of PBDEs accumulation in the brain among multiple vertebrate species.

\section{Materials and methods}

\subsection{Chemicals}

PBDE analytical standard solution EO-5278 (including unlabeled BDE-28, -47, -99, -100, -153, -154, -183, and -209), surrogate standard solution $\left({ }^{13} \mathrm{C}\right.$-labeled $\left.\mathrm{BDE}-209\right)$ and recovery standard solution (BDE-71) were purchased from Cambridge Isotope Laboratories (Andover, MA, USA). The standard solution EO-5278 was also used in a spiked matrix for initial precision and recovery studies. All solvents were of a grade suitable for pesticide residue analysis (Tedia, Fairfield, OH, USA).

\subsection{Sample collection}

The sampling site $\left(121^{\circ} 13^{\prime} 21^{\prime \prime}-121^{\circ} 13^{\prime} 36^{\prime \prime} \mathrm{E} ; \quad 28^{\circ} 21^{\prime} 14^{\prime \prime}-\right.$ $28^{\circ} 21^{\prime} 41^{\prime \prime} \mathrm{N}$ ) was located in Nanwan village of Wenling town in Taizhou City, Zhejiang Province, China (Fig. 1). At this sampling site, there were many family-run workshops recycling e-waste containing PBDEs, resulting in PBDEs pollution of the environment. Particularly, discarded plastic powders are stacked around inside Nanwan village (Chi et al., 2014; Qin et al., 2011). Thus, the whole village can be seen as one large e-waste recycling site. Five kinds of common vertebrates were collected from Nanwan village between 2008 and 2014. Fish (weever (Lateolabrax japonicas), $n=4$; large yellow croaker (Pseudosciaena crocea), $n=4$; blackhead seabream (Acanthopagrus schlegel), $n=2$; crucian carp (Carassius carassius), $n=5$; flathead grey mullet (Mugil cephalus), $n=5$ ) were obtained from a fish farm. Ducks (Anas domestica, $n=6$ ), and chickens (Gallus domesticus, $n=9$ ) were domesticated and purchased from local farmers. Frogs (Rana limnocharis, $n=22$; Rana nigromaculata, $n=3$ ) and mice (Microtus arvalis, $n=13$ ) were wild and obtained from paddy fields. More detailed information on the animals is provided in the Supporting Information (Table S1).

After euthanasia, fish were wrapped in aluminum foil and immediately transported to the laboratory at $4{ }^{\circ} \mathrm{C}$ within $24 \mathrm{~h}$. Other animals were alive during the transport process. After arriving at the laboratory, liver, muscle and brain tissues were immediately excised from each animal after euthanasia. Tissues

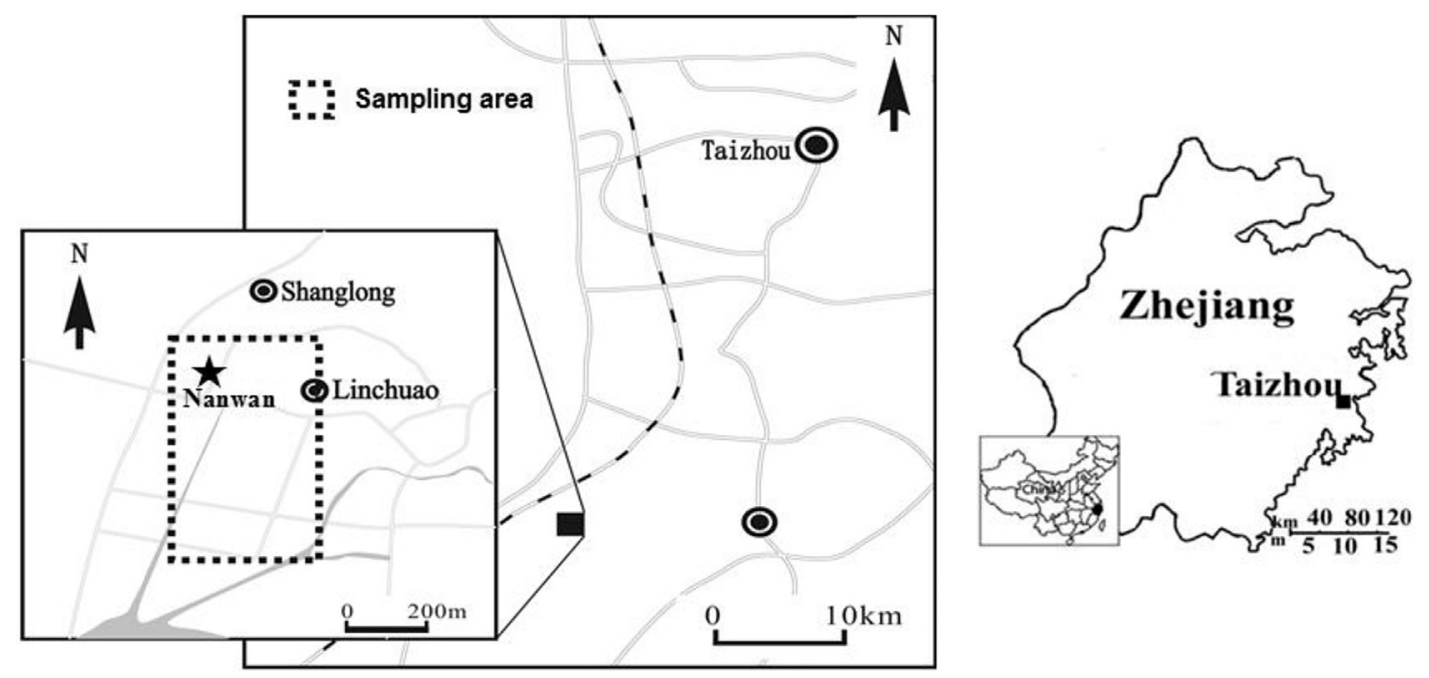

Fig. 1. Sampling location in Taizhou, Zhejiang Province, China. Samples were collected in one e-waste recycling village (Nanwan, $\star$ ). 
from some individuals were pooled because they were too small for PBDEs analysis. All tissue samples were washed with deionized water, wrapped with two layers of aluminum foil, and stored at $-20^{\circ} \mathrm{C}$ in the dark until further analysis.

\subsection{Sample preparation and analysis}

Tissue samples were extracted, cleaned and analyzed according to previously reported methods (Liu et al., 2011, 2015) with minor modifications. Briefly, after freeze-drying, homogenizing with anhydrous sodium sulfate and spiking with surrogate standard $\left({ }^{13}\right.$ C-labeled BDE-209) and recovery standard (BDE-71), samples were extracted twice with $n$-hexane/dichloromethane (1:1, vol/vol) by ultrasonic agitation. Then, the combined extracts were concentrated to $2 \mathrm{~mL}$ and further purified on a multilayer silica gel column. The eluate containing the PBDE mixture was dried in a rotary evaporator, and then reduced to $20 \mu \mathrm{L}$ under a gentle nitrogen stream. The final extract was transferred to gas chromatography (GC) vials. Throughout the extraction, cleanup and analysis, the analytes were protected from light by wrapping the containers with aluminum foil, or by using amber glassware.

PBDEs were analyzed with gas chromatograph 6890 coupled to a mass spectrometer 5973 (Agilent Technologies, Palo Alto, CA, USA) using negative chemical ionization ( $\mathrm{NCI}$ ) in the selected-ion monitoring (SIM) mode. The GC column was DB-5MS-fused silica capillaries ( $15 \mathrm{~m} \times 0.25 \mathrm{~mm}$ i.d., $0.25 \mu \mathrm{m}$ film thickness). The injector and interface temperatures were $265{ }^{\circ} \mathrm{C}$ and $300{ }^{\circ} \mathrm{C}$, respectively. Methane was used as the chemical ionization moderating gas, and helium as the carrier gas, at a flow rate of $1.0 \mathrm{~mL} / \mathrm{min}$. The GC oven-temperature program was carried out as follows: isothermal at $100^{\circ} \mathrm{C}$, held for $2 \mathrm{~min}$, increased to $200^{\circ} \mathrm{C}$ at $10{ }^{\circ} \mathrm{C} / \mathrm{min}$, then to $300{ }^{\circ} \mathrm{C}$ at $20^{\circ} \mathrm{C} / \mathrm{min}$, held for $20 \mathrm{~min}$. The ion fragments $\mathrm{m} / \mathrm{z} 79$ and 81 were monitored for the tri-to hepta-BDE congeners; $\mathrm{m} / \mathrm{z} 488.7$ and 486.7 for BDE-209; and $\mathrm{m} / \mathrm{z} 492.7$ and 494.7 for ${ }^{13} \mathrm{C}$-labeled BDE-209.

\subsection{Quality assurance and quality control $(\mathrm{QA} / \mathrm{QC})$}

To avoid potential sample contamination and PBDE degradation, appropriate handling procedures were adopted from sample collection to chemical analysis. One procedural blank was run for each batch of nine samples to check for contamination during the analytical process. The quantities of PBDE in the procedure blanks were well below $10 \%$ of the levels detected in the samples, and, therefore, no corrective action was taken. The identification of PBDE congeners depended on comparison of their retention times, and the ratios of the monitored ions, with those of the original congener standards. The precision of the method was determined by analyzing muscle tissue of fish spiked with PBDE standards $(n=6$, relative $S D<15 \%$ ). Recoveries ranged from $85 \%$ to $115 \%$ for all the congeners detected in spiked blanks. The recovery of the analytical method was monitored using BDE-71 and ${ }^{13} \mathrm{C}$-labeled BDE-209. Mean recoveries ( \pm SD) of BDE-71 and ${ }^{13} \mathrm{C}$-labeled BDE209 were $98 \pm 18 \%$ and $87 \pm 10 \%$, respectively (Table S2). The detection limits (LODs), defined as three times the noise level, were 0.008-0.05 ng/g wet weight (ww) for tri-to hepta-BDEs and $0.10 \mathrm{ng} / \mathrm{g}$ ww for BDE-209. Concentrations below the LOD were treated as zero when calculating the sum of the PBDE concentrations.

\subsection{Data analysis}

Data were tested for normality using the Kolmogorov-Smirnov test before statistical analysis. Differences in PBDE concentrations among tissues, and in the brain/liver concentration ratios $(B / L)$ of
PBDE congeners among animal species, were analyzed by the Kruskal-Wallis $\mathrm{H}$ test. Significant differences in the B/L ratios between different PBDE congeners in vertebrates were examined using Duncan's multiple range test. Significant differences in B/L ratios of different PBDE congeners in the same species were tested by Duncan's multiple range tests. Statistical analysis was performed using the statistical software program SPSS 16.0 (SPSS Inc., Chicago, IL, USA). A value of $p<0.05$ was considered statistically significant.

\section{Results and discussion}

\subsection{PBDE levels in the brain compared with those in other tissues}

No data were available for frog muscle tissues because of loss of the samples. Some brain and liver samples from fish and frogs were too small to obtain their lipid contents by gravimetric methods. Thus, PBDE concentrations in this study are expressed on a wetweight basis. PBDEs were detected in all tested tissues of all animals, as shown in Table 1. The sum of PBDEs ( $\sum$ PBDE) in individual animal tissues covered a concentration range of four orders of magnitude. The lowest $\sum$ PBDE level $(0.02 \mathrm{ng} / \mathrm{g} \mathrm{ww})$ was detected in fish muscle and the highest (206 ng/g ww) in mice liver. The PBDE levels we detected in the animal tissues were generally comparable to those previously reported in biotic samples from other e-waste recycling sites (Luo et al., 2009; Wu et al., 2009; Zeng et al., 2013; Zhang et al., 2010). However, the PBDE concentrations in our study were generally $1-2$ orders of magnitude greater than the general levels in China (Li et al., 2010; Wan et al., 2008; Wu et al., 2009) (Table S3), confirming the level of PBDE contamination at this sampling site, presumably attributable to e-waste recycling.

The mean values of $\sum$ PBDE in brain tissues were compared with those in other tissues among different animals. Significant differences were found between the brain and other tissues in mice, chickens, ducks and frogs $(p<0.05)$. The mean $\sum$ PBDE level in mice brains was about one fifth that in the liver and half that in the muscle. For ducks and chickens, the mean levels of PBDEs in their brains were only about one tenth that in their livers, and one quarter to one eighth levels in their muscles. In frogs, the mean $\sum$ PBDE levels in brain tissue were about half that in the liver. Our findings are consistent with previous studies involving PBDE accumulation in the brain. Staskal et al. (2006a; 2006b) reported lower PBDE concentrations in the brain relative to the liver in experimental mice exposed to PBDEs. Gebbink et al. (2008) reported that, on a wet-weight basis, PBDE concentrations in the brains were one twentieth of those in the livers of polar bears from East Greenland. Additionally, on a lipid-weight basis, PBDE concentrations in brains were found to be significantly lower than those in other tissues of ducks, chickens, buzzards, owls and sparrow hawks (Qin et al., 2011; Voorspoels et al., 2006, 2007; Yang et al., 2011; Zhang et al., 2008). A recent study of wild frogs also showed lower accumulation of PBDEs in the brain relative to other tissues (Li et al., 2014).

The tissue distributions of lipophilic pollutants are believed to depend primarily on the lipid contents of tissues (Matthews and Dedrick, 1984). The lipid content of the brain of mice was $7.00 \%$, much higher than that of liver (1.91\%) and muscle tissues (0.59\%), in the present study, the lowest concentrations of PBDEs were found in the brains of mice, ducks and chickens. Previous studies suggested that the BBB could be partly responsible for reduced PBDE accumulation in the brain relative to in other tissues (Barón et al., 2015; Voorspoels et al., 2006; Yang et al., 2011). Our results on several vertebrates support this proposal.

By contrast, it was noted that the mean concentrations of PBDEs in brain samples of five fish species were significantly higher than 


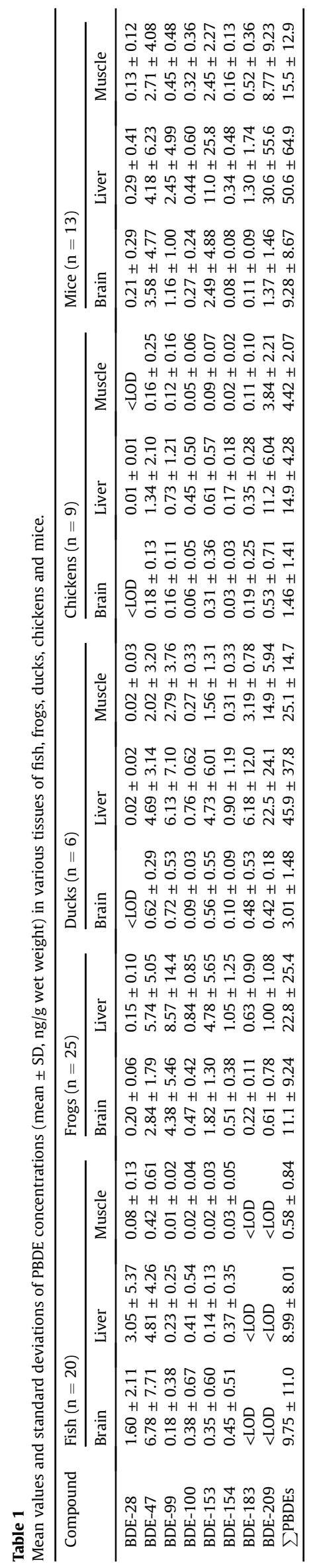

those in muscle tissues $(p<0.05)$. The mean $\sum$ PBDE levels in their brains were also generally higher than those in liver samples, but the differences lacked statistical significance. Our findings are in agreement with those reported for wild silverside (Barni et al., 2014). Likewise, it was reported that PCBs were accumulated preferentially in the brain relative to the liver and muscle in bluefish (Deshpande et al., 2013). Based on data concerning PCB concentrations in the brain compared with those in other tissues among different vertebrates, Bachour et al. (1998) inferred that the $\mathrm{BBB}$ of fish was considerably less efficient than that of mammals in terms of protection against PCB accumulation in the brain. In the present study, our observation of comparable or slightly higher concentrations in fish brains than in fish livers suggests that the high accumulation of PBDEs in the fish brain results from a lack of protection by the BBB. In contrast to most studies, however, Nilsen et al. (2014) recently reported that the levels of PBDEs in the brain were 2-3 times lower than levels in the liver in largescale suckers (Catostomus macrocheilus). The current data do not provide a reasonable explanation for the different findings concerning PBDE accumulation in the brain among fish species. It seems that PBDEs accumulate in the brains of certain fish species in a different manner from that in other fish species.

\subsection{PBDE congener profiles in the brain compared with other tissues}

Animals in the present study exhibited different PBDE congener profiles (Fig. 2). The most abundant congener in the brain of mice was BDE-47, which contributed to $39.1 \%$, followed by BDE-153 (19.7\%) and BDE-99 (14.0\%). BDE-209 contributed only $16.6 \%$ to the total PBDE concentrations in the brain, but dominated in the liver (49.0\%) and muscle (43.7\%). In ducks, BDE-47 and BDE-99 as the most abundant congener were observed in the brain, with BDE-209 accounting for 18.0\%. In contrast, BDE-209 accounted for $41.9 \%$ and $63.4 \%$ of $\sum$ PBDE in the liver and muscle, respectively. In chickens, the percentages of low brominated congeners such as BDE-47 and BDE-99 were higher in the brain (28.9\%) than in liver (14.4\%) and muscle (9.43\%). Correspondingly, the contribution of BDE-209 in chicken brain (31.5\% of $\sum$ PBDE) was approximately half to one third that in liver (73.4\%) and muscle tissues (83.2\%).

Previous studies have described similar findings to ours (Yang et al., 2011; Zheng et al., 2015). Huwe et al. (2008) found that BDE-209 and other higher brominated congeners were absent from the brain of experimental rats following PBDE exposure, but represented significantly elevated percentages of total PBDEs in

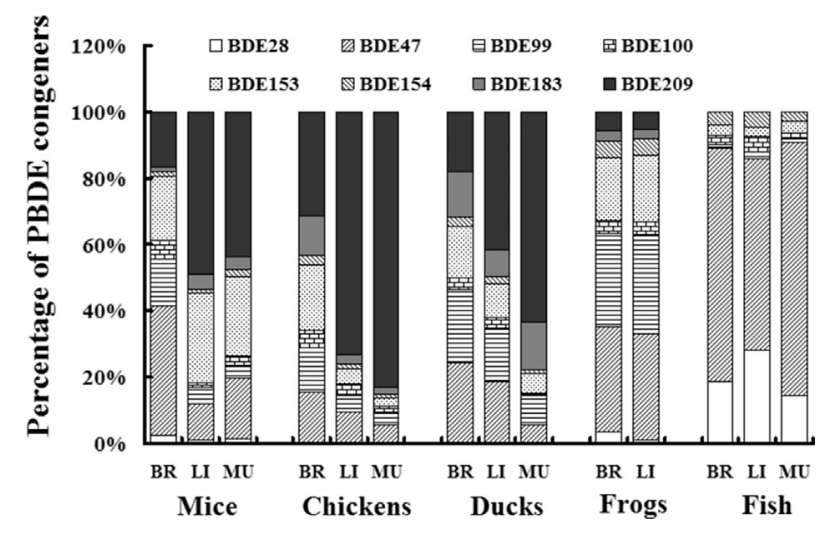

Fig. 2. Congener profiles of PBDEs (BDE-28, $-47,-99,-100,-153,-154,-183$ and -209 ) in brain, liver and muscle tissues (BR: brain, LI: liver, MU: muscle) of mice, chickens, ducks, frogs and fish. 
liver and blood samples. In a recent study, BDE-47 was observed as the most abundant congener in brain samples of chickens collected from an e-waste site, while BDE-209 dominated in other tissues (Zheng et al., 2015). Isobe et al. (2009) detected BDE-209 and other high brominated PBDE congeners in blubber, liver and muscle tissues of striped dolphins, but not in brain tissue. Similarly, lower percentages of high brominated congeners and higher percentages of low brominated congeners were found in the brain relative to other tissues in polar bears (Gebbink et al., 2008). Together with our study, these reports show that the high brominated congeners (such as BDE-209) exhibit lower accumulation relative to low brominated congeners (such as BDE-47) in the brain in comparison with other tissues of mammals and birds. In another words, the brains of these animals seem to be protected more effectively against accumulation of high brominated congeners than low brominated congeners.

Similar PBDE congener profiles were found in brain, liver and muscle tissues of fish with not statistically significantly differences. Different with mice, chickens and duck, no BDE-209 was detected in the tissues of the fish species examined; BDE-47 and BDE-28 were the major congeners, followed by BDE-153, BDE-154, and BDE-100 (Fig. 2). The PBDE congener profile was similar to a previous report on mud carp and northern snakehead from a natural pond near e-waste recycling workshops in South China (Zeng et al., 2013). Similarly, most previous studies did not detect BDE-209 in wild and experimental fish (Allchin et al., 1999; Luo et al., 2007; Stapleton et al., 2004a; Yu et al., 2009). The absence of BDE-209 in fish specimens is generally explained by the combined effects of lower bioavailability associated with its high octanol-water partition coefficient $\left(\log K_{\mathrm{ow}}=12.1\right)$ and its high molecular weight ( $\mathrm{m} / \mathrm{z}=959 \mathrm{amu}$ ) (Stapleton et al., 2004b, 2006). However, in contrast to earlier reports, several recent studies have detected BDE-209 in some wild and experimental fish (Munschy et al., 2011; Nyholm et al., 2009; Wan et al., 2013). The reason of detecting different levels of BDE-209 may be due to the different efficiencies of uptake, elimination and metabolism for BDE-209 among various fish species. Laboratory studies have reported the uptake efficiencies of BDE-209 were $1.4 \% \pm 0.9 \%$ for juvenile common sole (Munschy et al., 2011), 0.62\% for zebrafish (Nyholm et al., 2009), $0.44 \%$ for rainbow trout (Stapleton et al., 2006 ), and $0.5 \% \pm 0.2 \%$ for Chinese sturgeon (Wan et al., 2013), respectively. In vitro metabolism studies also revealed that $65.6 \%$ of BDE-209 was biotransformed in liver microsomes of Chinese sturgeon which was lower than those in rainbow trout and common carp. So far the fate and behavior of BDE-209 has been poorly understood, thus more bioaccumulation studies in the future are needed to confirm different findings of BDE 209 accumulation in fish.

In frogs, the brain and liver exhibited statistically similar PBDE congener profiles. BDE-47 and BDE-99 were the most abundant congeners, followed by BDE-153. The sum of BDE-47, BDE-99 and BDE-153 collectively accounted for $79.1 \%$ and $82.6 \%$ of the total PBDE concentrations in the brain and liver, respectively. Similar results were observed in our previous study (Liu et al., 2011), although in another study BDE-99 and BDE-153 were found to be the dominant congeners (Wu et al., 2009). Together, the data show that medium brominated congeners are the main congeners in frogs, suggesting that amphibians have a unique PBDE congener profile intermediate between that of aquatic (low brominated congeners being the main congeners) and terrestrial species (high brominated congeners being the main congeners).

\subsection{Brain/liver ratios of PBDE concentrations}

To further compare PBDE accumulation in the brain between different vertebrates, we calculated brain/liver (B/L) ratios of PBDE concentrations for each animal. As shown in Fig. 3, B/L ratios were less than 1 in all species except for fish, indicating preferential distribution of PBDEs in the liver of these species. The median values of the $\mathrm{B} / \mathrm{L}$ ratio for mice, chickens and ducks were $0.27,0.08$, and 0.10 , respectively. Pairwise comparisons revealed no significant differences between the ratios in these three species. However, the median value of $\mathrm{B} / \mathrm{L}$ ratio for frogs was 0.66 , which was higher than the values for mice, chickens and ducks. There was a significant difference in $\mathrm{B} / \mathrm{L}$ ratios between frogs and chickens $(p<0.05)$. The median $\mathrm{B} / \mathrm{L}$ ratios for the five fish species were rather similar and not significantly different from each other: $0.94,1.34,1.76,1.20$, and 0.74 for L. japonicas, P. crocea, A. schlegel, M. cephalus, and C. carassius respectively. Thus we combined the data for the five fish species to calculate a $\mathrm{B} / \mathrm{L}$ ratio for fish, which had a median value of 1.20. Significant differences in the $B / L$ ratio were observed between fish and the other species $(p<0.05)$. Based on comparison of the $\mathrm{B} / \mathrm{L}$ ratios between these vertebrate groups, it is concluded that PBDEs accumulation in the brain displays species-specific differences among vertebrate groups. PBDEs accumulation in the brain was most marked in fish, followed by frogs, and the lowest accumulation occurred in the brains of mammals and birds. These findings lead us to speculate that, compared with lower vertebrates, higher vertebrates might have a more effective capacity to prevent PBDEs from entering the brain, or to eliminate them from the brain. This capacity appears to coincide with the evolution of the BBB in vertebrates. Fish have primitive BBBs that are composed of glial cells rather than endothelial cells, whereas mammals have developed advanced BBBs consisting of endothelial cells and glial cells that allow for a greater selectivity against the passage of potentially detrimental molecules or organisms from the blood to the brain (Bundgaard and Abbott, 2008; Risau and Wolburg, 1990). Our assumption accords with the opinion of Bachour et al. (1998), who suggested that the BBB of fish was less efficient than that of mammals with respect to protection against $\mathrm{PCB}$ accumulation in the brain.

Further experimental studies are needed to evaluate the specific role of the BBB in preventing the entry and accumulation of PBDEs in the brain among different vertebrates. Besides differences in BBB function among vertebrates, patterns of PBDEs accumulation in the brain could result from other factors, such as differences in lipid compositions of the brain relative to the liver and lipid mobilization (Barni et al., 2014; Jorgensen et al., 1997; Yang et al., 2011; Yordy et al., 2010). Previous studies in vitro have shown that the affinity of PCBs for neutral lipids (triglycerides) is higher than for polar

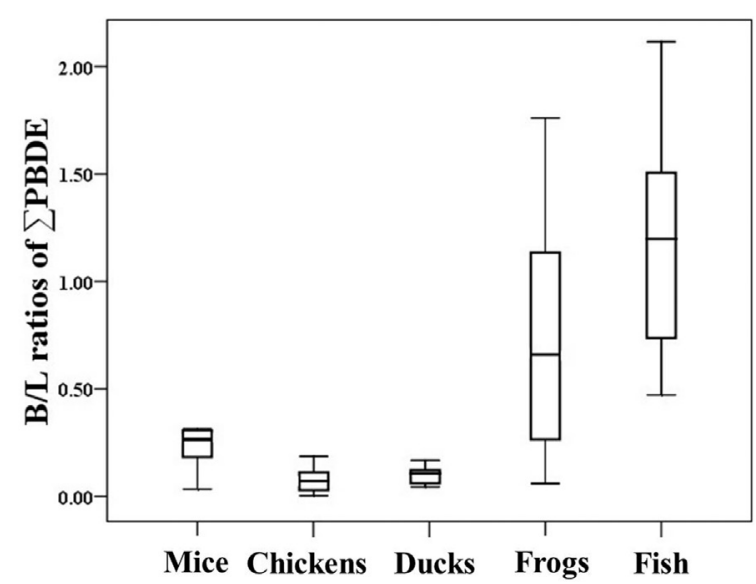

Fig. 3. Boxplot (minimum, $25 \%$ quartile, median, $75 \%$ quartile, maximum, outliers were not displayed) of brain/liver (B/L) ratios of $\sum$ PBDE concentrations in mice, ducks, chickens, frogs, and fish. 

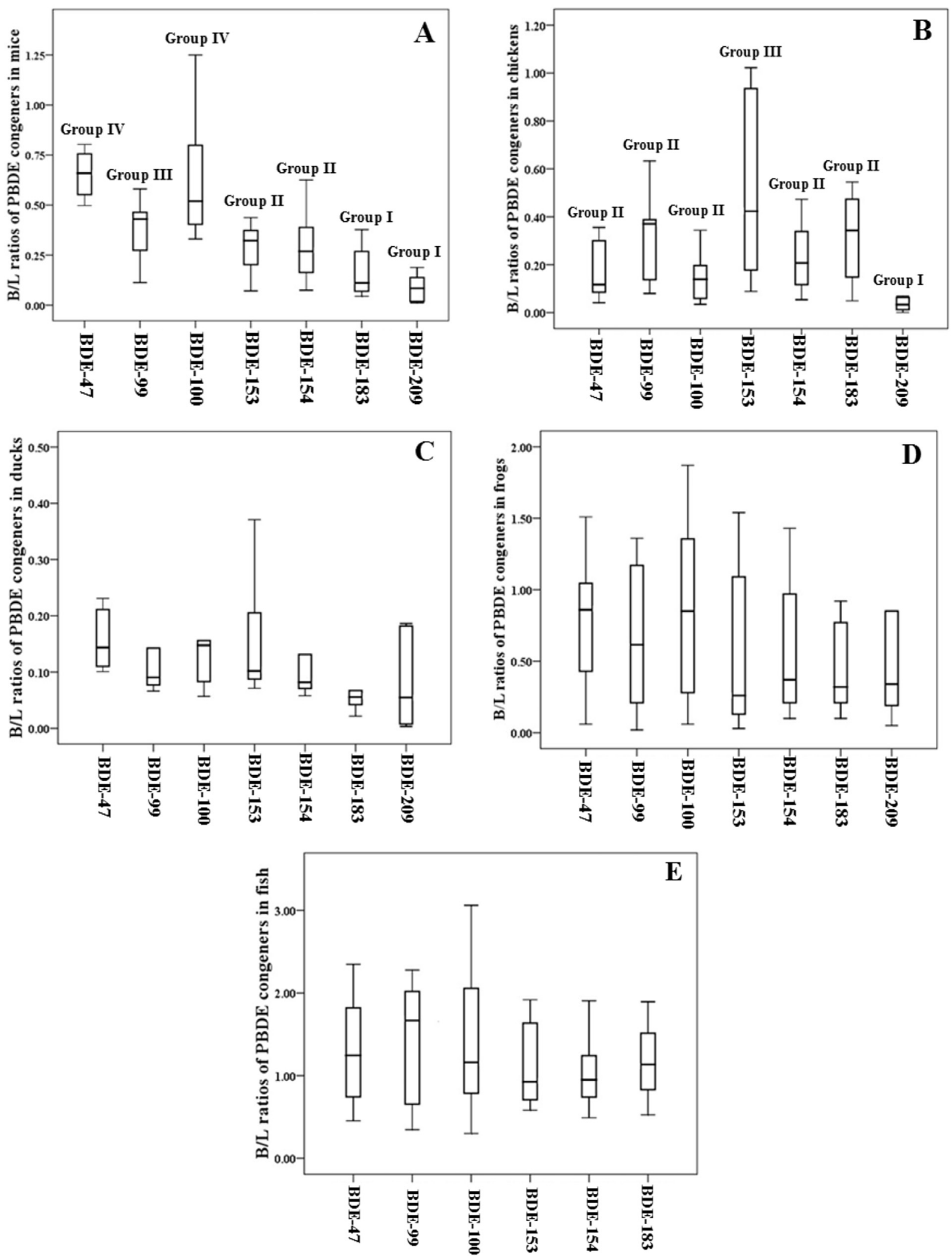

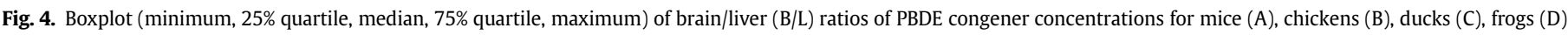

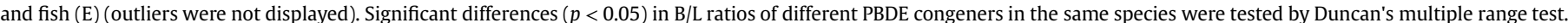

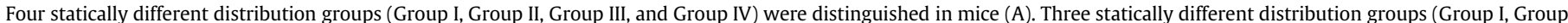
II, and Group III) were distinguished in chickens (B). No significant difference was observed in other species. 
lipids (phospholipids) (Sandermann, 2003), and this may also apply to PBDEs. The brain contains higher quantities of polar lipids (phospholipids and sphingolipids) and smaller amounts of triglycerides relative to the liver and other tissues (Weijs et al., 2011), possibly partly accounting for lower concentrations of PBDEs in the brain.

The $\mathrm{B} / \mathrm{L}$ ratios of individual PBDE congeners for all species are shown in Fig. 4. Due to the low frequency of detection in mice, duck and chicken specimens, the $\mathrm{B} / \mathrm{L}$ ratio of $\mathrm{BDE}-28$ was not calculated. The median $\mathrm{B} / \mathrm{L}$ ratios of all PBDE congeners were less than 1 in mice, ducks, chickens and frogs, ranging from 0.11 to 0.78 in mice (Fig. 4A), 0.05-0.44 in chickens (Fig. 4B), 0.05-0.47 in ducks (Fig. 4C), and 0.41-0.86 in frogs (Fig. 4D). Significant differences in $\mathrm{B} / \mathrm{L}$ ratios of different PBDE congeners in the same species were tested by Duncan's multiple range tests. As shown in Fig. 4A, four statistically different distribution groups could be distinguished in mice: 1) BDE-209 and BDE-183; 2) BDE-153 and BDE-154; 3) BDE99 ; 4) BDE-47 and BDE-100. The B/L ratios clearly exhibited a declining trend with increasing bromine number in mice. In chickens, PBDE congeners were divided into three statistically different distribution groups by Duncan's multiple range tests: BDE-209, BDE-153 and the others (Fig. 4B). No significant differences in $\mathrm{B} / \mathrm{L}$ ratios between $\mathrm{PBDE}$ congeners were observed for ducks and frogs. However, the lower values of B/L ratios of BDE-209 than low brominated congeners were also observed in ducks (Fig. 4C) and frogs (Fig. 4D), like mice and chickens. Our observations suggest that low brominated congeners might have a higher capacity to penetrate the BBB and accumulate in the brain, whereas high brominated congeners such as BDE-209 might have less potency to go through the barrier, perhaps as a result of the high molecular weight and size of high brominated congeners (Li et al., 2014; Yordy et al., 2010). In another words, the BBB might hinder high brominated congeners such as BDE-209 more effectively than low brominated congeners, which is consistent with previous studies (Qin et al., 2011; Yang et al., 2011). In contrast to the other species, the B/L ratios of PBDE congeners ranged from 0.99 to 1.67 in fish (Fig. 4E), with no statically significant differences. These results suggest that $\mathrm{PBDE}$ congeners might have a similar capacity to penetrate the BBB of fish and preferentially accumulate in the brain compared with the liver. Significant differences were found between fish and mice, ducks, chickens and frogs $(p<0.05)$, and all the median values of $\mathrm{B} / \mathrm{L}$ ratios for PBDE congeners in fish were higher than 1, suggesting PBDE congeners might transport across the BBB of fish more easily than other vertebrates. These results further show species-specific differences in PBDE accumulation in the brain between fish and other vertebrates.

\section{Conclusions}

This study presents new data regarding the accumulation of PBDEs in the brain among different vertebrates, by comparing its distribution between brain and other tissues (liver and muscle). PBDEs are preferentially distributed in the liver of mice, chickens, ducks and frogs. Accumulation in the brain of the investigated fish species, suggests that the BBB of fish possibly provides little protection against PBDEs compared with the BBB of high-level vertebrates. Furthermore, different $\mathrm{B} / \mathrm{L}$ ratios for PBDEs indicate that there may be species-specific differences among vertebrate groups in the efficiency of the BBB in preventing entry of congeners into the brain. Low brominated congeners like BDE-28, -47, and -99 presented higher $\mathrm{B} / \mathrm{L}$ ratios compared with high brominated congeners (BDE-209), suggesting the BBB might hinder more effectively high brominated congeners than low brominated congeners. Experimental studies about PBDE transport across the BBB are needed to confirm our findings.

\section{Acknowledgments}

This work was supported by grants from the Strategic Priority Research Program of the Chinese Academy of Sciences (XDB14040102), National Natural Science Foundation of China (21077125), and State Key laboratory of Environmental Chemistry and Ecotoxicology, RCEES, CAS (KF2014-20).

\section{Appendix A. Supplementary data}

Supplementary data related to this article can be found at http:// dx.doi.org/10.1016/j.envpol.2016.08.091.

\section{References}

Abafe, O.A., Martincigh, B.S., 2015. Polybrominated diphenyl ethers and polychlorinated biphenyls in indoor dust in Durban, South Africa. Indoor Air 25, 547-556.

Allchin, C.R., Law, R.J., Morris, S., 1999. Polybrominated diphenylethers in sediments and biota downstream of potential sources in the UK. Environ. Pollut. 105 197-207.

Bachour, G., Failing, K., Georgii, S., Elmadfa, I., Brunn, H., 1998. Species and organ dependence of PCB contamination in fish, foxes, roe deer, and humans. Arch. Environ. Contam. Toxicol. 35, 666-673.

Barni, M.F., Gonzalez, M., Miglioranza, K.S., 2014. Assessment of persistent organic pollutants accumulation and lipid peroxidation in two reproductive stages of wild silverside (Odontesthes bonariensis). Ecotoxicol. Environ. Saf. 99, 45-53.

Barón, E., Hauler, C., Gallistl, C., Giménez, J., Gauffier, P., Castillo, J.J., FernaándezMaldonado, C., de Stephanis, R., Vetter, W., Eljarrat, E., Barceló, D., 2015. Halogenated natural products in dolphins: brain-blubber distribution and comparison with halogenated flame retardants. Environ. Sci. Technol. 49, 9073-9083.

Basu, N., Scheuhammer, A.M., O'Brien, M., 2007. Polychlorinated biphenyls, organochlorinated pesticides, and polybrominated diphenyl ethers in the cerebra cortex of wild river otters (Lontra canadensis). Environ. Pollut. 149, 25-30.

Bernacki, J., Dobrowolska, A., Nierwińska, K., Małecki, A., 2008. Physiology and pharmacological role of the blood-brain barrier. Pharmacol. Rep. 60, 600-622.

Bundgaard, M., Abbott, N.J., 2008. All vertebrates started out with a glial bloodbrain barrier 4-500 million years ago. Glia 56, 699-708.

Chi, X., Wang, M.Y., Reuter, M.A., 2014. E-waste collection channels and household recycling behaviors in Taizhou of China. J. Clean. Prod. 80, 87-95.

Stockholm Convention, 2009. Report of the Conference of the Parties of the Stockholm Convention on Persistent Organic Pollutants on the Work of its Fourth Meeting. UNEP/POPS/COP.4/38. 8 May 2009. Stockholm Convention, Geneva, Switzerland.

Costa, L.G., de Laat, R., Tagliaferri, S., Pellacani, C., 2014. A mechanistic view of polybrominated diphenyl ether (PBDE) developmental neurotoxicity. Toxicol. Lett. 230, 282-294.

Costa, L.G., Tagliaferri, S., Roqué, P.., Pellacani, C., 2016. Role of glutamate receptors in tetrabrominated diphenyl ether (BDE-47) neurotoxicity in mouse cerebellar granule neurons. Toxicol. Lett. 241, 159-166.

Deshpande, A.D., Dockum, B.W., Cleary, T., Farrington, C., Wieczorek, D., 2013. Bioaccumulation of polychlorinated biphenyls and organochlorine pesticides in young-of-the-year bluefish (Pomatomus saltatrix) in the vicinity of a Superfund Site in New Bedford Harbor, Massachusetts, and in the adjacent waters. Mar. Pollut. Bull. 72, 146-164.

Gebbink, W.A., Sonne, C., Dietz, R., Kirkegaard, M., Riget, F.F., Born, E.W., Muir, D.C. Letcher, R.J., 2008. Tissue-specific congener composition of organohalogen and metabolite contaminants in East Greenland polar bears (Ursus maritimus). Environ. Pollut. 152, 621-629.

Han, W., Feng, J., Gu, Z., Chen, D., Wu, M., Fu, J., 2009. Polybrominated diphenyl ethers in the atmosphere of Taizhou, a major e-waste dismantling area in China B. Environ. Contam. Tox 83, 783-788.

Hassan, A.A., Rylander, C., Brustad, M., Sandanger, T.M., 2013. Persistent organic pollutants in meat, liver, tallow and bone marrow from semi-domesticated reindeer (Rangifer tarandus tarandus L.) in Northern Norway. Acta Vet. Scand. $55,57$.

Huwe, J.K., Hakk, H., Birnbaum, L.S., 2008. Tissue distribution of polybrominated diphenyl ethers in male rats and implications for biomonitoring. Environ. Sci. Technol. 42, 7018-7024.

Isobe, T., Ochi, Y., Ramu, K., Yamamoto, T., Tajima, Y., Yamada, T.K., Amano, M., Miyazaki, N., Takahashi, S., Tanabe, S., 2009. Organohalogen contaminants in striped dolphins (Stenella coeruleoalba) from Japan: present contamination status, body distribution and temporal trends (1978-2003). Mar. Pollut. Bull. 58 396-401.

Jorgensen, E.H., Burkow, I.C., Foshaug, H., Killie, B., Ingebrigtsen, K., 1997. Influence of lipid status on tissue distribution of the persistent organic pollutant octachlorostyrene in Arctic charr (Salvelinus alpinus). Comp. Biochem. Physiol. Pharmacol. Toxicol. Endocrinol. 118, 311-318.

Kodavanti, P.R.S., Royland, J.E., Osorio, C., Winnik, W.M., Ortiz, P., Lei, L 
Ramabhadran, R., Alzate, O., 2015. Developmental exposure to a commercial PBDE mixture: effects on protein networks in the cerebellum and Hippocampus of rats. Environ. Health Perspect. 123, 428-436.

Li, Q., Yan, C., Luo, Z., Zhang, X., 2010. Occurrence and levels of polybrominated diphenyl ethers (PBDEs) in recent sediments and marine organisms from Xiamen offshore areas, China. Mar. Pollut. Bull. 60, 464-469.

Li, L., Wang, W.Y., Lv, Q.X., Ben, Y.J., Li, X.H., 2014. Bioavailability and tissue distribution of Dechloranes in wild frogs (Rana limnocharis) from an e-waste recycling area in Southeast China. J. Environ. Sci. 26, 636-642.

Liu, P.Y., Du, G.D., Zhao, Y.X., Mu, Y.S., Zhang, A.Q., Qin, Z.F., Zhang, X.Y., Yan, S.S., Li, Y., Wei, R.G., Qin, X.F., Yang, Y.J., 2011. Bioaccumulation, maternal transfer and elimination of polybrominated diphenyl ethers in wild frogs. Chemosphere 84, 972-978.

Liu, P.Y., Chen, X.R., Zhao, Y.X., Li, Y.Y., Qin, X.F., Qin, Z.F., 2015. Changes of polybrominated diphenyl ether concentrations in ducks with background exposure level and time. Chemosphere 118, 253-260.

Luo, Q., Wong, M.H., Cai, Z.W., 2007. Determination of polybrominated diphenyl ethers in freshwater fishes from a river polluted by e-wastes. Talanta 72 , 1644-1649.

Luo, X.J., Liu, J., Luo, Y., Zhang, X.L., Wu, J.P., Lin, Z., Chen, S.J., Mai, B.X., Yang, Z.Y., 2009. Polybrominated diphenyl ethers (PBDEs) in free-range domestic fowl from an e-waste recycling site in South China: levels, profile and human dietary exposure. Environ. Int. 35, 253-258.

Matthews, H.B., Dedrick, R.L., 1984. Pharmacokinetics of PCBs. Annu. Rev Pharmacol Toxicol 24, 85-103.

Munschy, C., Héas-Moisan, K., Tixier, C., Olivier, N., Gastineau, O., Le Bayon, N., Buchet, V., 2011. Dietary exposure of juvenile common sole (Solea solea L.) to polybrominated diphenyl ethers (PBDEs): Part 1. Bioaccumulation and elimination kinetics of individual congeners and their debrominated metabolites Environ. Pollut. 159, 229-237.

Nilsen, E., Zaugg, S., Alvarez, D., Morace, J., Waite, I., Counihan, T., Hardiman, J., Torres, L., Patiño, R., Mesa, M., Grove, R., 2014. Contaminants of legacy and emerging concern in largescale suckers (Catostomus macrocheilus) and the foodweb in the lower Columbia River, Oregon and Washington, USA. Sci. Tota Environ. 484, 344-352.

Nyholm, J.R., Norman, A., Norrgren, L., Haglund, P., Andersson, P.L., 2009. Uptake and biotransformation of structurally diverse brominated flame retardants in zebrafish (Danio rerio) after dietary exposure. Environ. Toxicol. Chem. 28, 1035-1042.

Pardridge, W.M., 2012. Drug transport across the blood-brain barrier. J. Cereb. Blood Flow. Metab. 32, 1959-1972.

Qin, X.F., Qin, Z.F., Li, Y., Zhao, Y.X., Xia, X.J., Yan, S.S., Tian, M., Zhao, X.R., Xu, X.B., Yang, Y.J., 2011. Polybrominated diphenyl ethers in chicken tissues and eggs from an electronic waste recycling area in southeast China. J. Environ. Sci. 23, 133-138.

Risau, W., Wolburg, H., 1990. Development of the blood-brain barrier. Trends Neurosci. 13, 174-178.

Sandermann, H., 2003. Differential lipid affinity of xenobiotics and natural compounds. FEBS Lett. 554, 165-168.

Stapleton, H.M., Alaee, M., Letcher, R.J., Baker, J.E., 2004a. Debromination of the flame retardant decabromodiphenyl ether by juvenile carp (Cyprinus carpio) following dietary exposure. Environ. Sci. Technol. 38, 112-119.

Stapleton, H.M., Letcher, R.J., Baker, J.E., 2004b. Debromination of polybrominated diphenyl ether congeners BDE 99 and BDE 183 in the intestinal tract of the common carp (Cyprinus carpio). Environ. Sci. Technol. 38, 1054-1061.

Stapleton, H.M., Brazil, B., Holbrook, R.D., Mitchelmore, C.L., Benedict, R. Konstantinov, A., Potter, D., 2006. In vivo and in vitro debromination of decabromodiphenyl ether (BDE-209) by juvenile rainbow trout and common carp.
Environ. Sci. Technol. 40, 4653-4658.

Staskal, D.F., Diliberto, J.J., Birnbaum, L.S., 2006a. Impact of repeated exposure on the toxicokinetics of BDE 47 in mice. Toxicol. Sci. 89, 380-385.

Staskal, D.F., Hakk, H., Bauer, D., Diliberto, J.J., Birnbaum, L.S., 2006b. Toxicokinetics of polybrominated diphenyl ether congeners 47, 99, 100, and 153 in mice. Toxicol. Sci. 94, 28-37.

Tang, X., Zeng, B., Hashmi, M.Z., Long, D., Yu, B., Ullah, N., Shen, C., Chen, Y., 2014. PBDEs and PCDDFs in surface soil taken from the Taizhou e-waste recycling area, China. Chem. Ecol. 30, 245-251.

Voorspoels, S., Covaci, A., Lepom, P., Jaspers, V.L., Schepens, P., 2006. Levels and distribution of polybrominated diphenyl ethers in various tissues of birds of prey. Environ. Pollut. 144, 218-227.

Voorspoels, S., Covaci, A., Jaspers, V.L.B., Neels, H., Schepens, P., 2007. Biomagnification of PBDEs in three small terrestrial food chains. Environ. Sci. Technol. 41, 411-416.

Wan, Y., Hu, J.Y., Zhang, K.,L.,A., 2008. Trophodynamics of polybrominated diphenyl ethers in the marine food web of Bohai Bay, North China. Environ. Sci. Technol. 42, 1078-1083.

Wan, Y., Zhang, K., Dong, Z.M., Hu, J.Y., 2013. Distribution is a major factor affecting bioaccumulation of decabro- minated diphenyl ether: Chinese sturgeon (Acipenser sinensis) as an example. Environ. Sci. Technol. 47, 2279-2286.

Weijs, L., Covaci, A., Yang, R.S., Das, K., Blust, R., 2011. A non-invasive approach to study lifetime exposure and bioaccumulation of PCBs in protected marine mammals: PBPK modeling in harbor porpoises. Toxicol. Appl. Pharmacol. 256, 136-145.

Wu, J.P., Luo, X.J., Zhang, Y., Chen, S.J., Mai, B.X., Guan, Y.T., Yang, Z.Y., 2009. Residues of polybrominated diphenyl ethers in frogs (Rana limnocharis) from a contaminated site, South China: tissue distribution, biomagnification, and maternal transfer. Environ. Sci. Technol. 43, 5212-5217.

Yang, Z.Z., Li, Y.F., Fu, S., Zhao, X.R., 2011. Special distribution of polybrominated diphenyl ethers in brain tissues of free-range domestic hens and ducks from a village near an electronic waste recycling site in South China. Bull. Environ. Contam. Toxicol. 86, 283-288.

Yordy, J.E. Pabst, D.A., McLellan, W.A., Wells, R.S, Rowles, T.K., Kucklick, J.R., 2010 Tissue-specific distribution and whole-body burden estimates of persistent organic pollutants in the bottlenose dolphin (Tursiops truncatus). Environ. Toxicol. Chem. 29, 1263-1673.

Yu, M., Luo, X.J., Wu, J.P., Chen, S.J., Mai, B.X., 2009. Bioaccumulation and trophic transfer of polybrominated diphenyl ethers (PBDEs) in biota from the Pearl River Estuary, South China. Environ. Int. 35, 1090-1095.

Yu, G., Bu, O. Cao, Z., Du, X., Xia, J., Wu, M., Huang, J., 2016. Brominated flame retardants (BFRs): a review on environmental contamination in China. Chemosphere 150, 479-490.

Zeng, Y.H., Luo, X.J., Yu, L.H., Chen, H.S., Wu, J.P., Chen, S.J., Mai, B.X., 2013. Using compound-specific stable carbon isotope analysis to trace metabolism and trophic transfer of PCBs and PBDEs in fish from an e-waste site, South China. Environ. Sci. Technol. 47, 4062-4068.

Zhang, S., Bursian, S., Martin, P.A., Chan, H.M., Martin, J.W., 2008. Dietary accumulation, disposition, and metabolism of technical pentabrominated diphenyl ether (de-71) in pregnant mink (Mustela vison) and their offspring. Environ. Toxicol. Chem. 27, 1184-1193.

Zhang, K., Wan, Y., An, L., Hu, J.Y., 2010. Trophodynamics of polybrominated diphenyl ethers and methoxylated polybrominated diphenyl ethers in a marine food web. Environ. Toxicol. Chem. 29, 2792-2799.

Zheng, X.B., Luo, X.J., Zheng, J., Zeng, Y.H., Mai, B.X., 2015. Contaminant sources, gastrointestinal absorption, and tissue distribution of organohalogenated pollutants in chicken from an e-waste site. Sci. Total Environ. 505, 1003-1010. 